\title{
Espacio público y protesta social en Colombia. Reflexiones durante la pandemia de la Covid-19
}

Public space and social protest in Colombia. Reflections during the Covid-19 pandemic Espaço público e protesto social na Colômbia. Reflexões durante a pandemia Covid-19

Pedro Arturo Martínez Osorio

Arquitecto, PhD. Design.

Corporación Universitaria del Caribe, Colombia.

pedro.martinez@cecar.edu.co

(iD) https://orcid.org/0000-0002-9024-0918

Alexandra Castellanos Tuirán

Arquitecta, MSc. Desarrollo y ambiente

Corporación Universitaria del Caribe, Colombia.

alexandra.castellanos@cecar.edu.co

(iD) https://orcid.org/0000-0003-3423-8714

\section{RESUMEN}

La situación de Colombia durante la crisis de la pandemia por la Covid-19, en los primeros meses de 2021, donde se presentaron múltiples manifestaciones en el espacio público en contra del gobierno, espacio que se puede describir como un escenario macabro de gran incertidumbre, deja muchos interrogantes sobre lo que significan esas acciones como representación de la sociedad colombiana. ¿El espacio público colombiano ha sido vetado como un escenario de dialogo necesario en toda sociedad democrática?

Palabras clave: Espacio público; Protesta social; Colombia.

\begin{abstract}
The situation in Colombia during the Covid-19 pandemic crisis, in the first months of 2021, where there were multiple demonstrations in public spaces against the government, a space that can be described as a macabre scenario of great uncertainty, leaves many questions about what those actions mean as a representation of Colombian society. Has the Colombian public space been vetoed as a necessary dialogue scenario in any democratic society?
\end{abstract}

Keywords: Public Space; Social Protest; Colombia. 


\section{RESUMO}

A situação na Colômbia durante a crise pandêmica Covid-19, nos primeiros meses de 2021, onde ocorreram múltiplas manifestações em espaços públicos contra o governo, um espaço que pode ser descrito como um cenário macabro de grande incerteza, deixa muitas dúvidas sobre o que essas ações significam como representação da sociedade colombiana. O espaço público colombiano foi vetado como cenário de diálogo necessário em qualquer sociedade democrática?

Palavras-chave: Espaço Público; Protesto Social; Colômbia.

Paramo et al. (2018) en su estudio sobre la habitabilidad del espacio público en las ciudades de América Latina reconocen la importancia de incluir al espacio público como un indicador de la calidad de vida urbana, considerando evaluaciones objetivas de elementos de la infraestructura y subjetivas a partir de las percepciones de los ciudadanos sobre las funciones que se cumplen en este; entre las principales funciones ellos mencionan:

La recreación, la integración social, la protección del clima, las celebraciones culturales, la comunicación, la expresión social (protestas), la seguridad (confianza en la policía, iluminación de parques, calles y plazas), la articulación entre los distintos componentes del espacio público, la equidad, la integración social que favorece accesibilidad, la calidad de los servicios (aseo, baños públicos, parqueaderos) y la estética de las construcciones y del paisaje (p. 348).

En ese contexto, los autores explican que las ciudades latinoamericanas padecen de problemáticas que afectan la calidad de vida; esto hace alusión al uso y funciones que cumple el espacio público. Referencian algunos estudios que identifican a las ciudades de América Latina entre el grupo de ciudades menos vivibles. Su análisis plantea que los principales aspectos que contribuyen a la baja calidad de vida en estas ciudades son, entre otros: la inestabilidad política, desigualdad, el narcotráfico, crimen callejero y secuestro (Paramo et al., 2018).

Por otra parte, Borja y Muxi (2003) explican que en el espacio público se hace visible una sociedad, ya que es el lugar de la representación. Los Espacios Urbanos están ligados a la historia de los momentos más representativos de la humanidad; en consecuencia, la representación de uno de los momentos trascendentales en la historia de Colombia como sociedad, se puede observar actualmente en los espacios públicos de las principales ciudades colombianas, precisamente durante uno de los fenómenos más complejos para la realidad mundial, como lo es la pandemia producto de la Covid-19.

En Colombia, los Artículos 20 y 37 de la Constitución Política de 1991, establecen el Derecho a la Protesta social, comprendiendo esta en los términos de manifestación pública, pacífica y garantía de libertad de expresión. También se encuentra la Ley 1453 de 2011, que especifica y regula los distintos escenarios de la protesta.

Cruz (2015) realiza un análisis sobre la perspectiva de la Ley 1453, la cual considera con una visión represiva, penalizando las diferentes conductas relacionadas con la protesta, dejando muchos aspectos a discreción de las autoridades, algunas veces en contra del mismo Derecho a la Protesta y libertad de expresión:

La Ley 1453 del 24 de junio del 2011, conocida como de "seguridad ciudadana", que reforma, entre otros, el Código Penal y el Código de Procedimiento Penal, mantiene una perspectiva puramente represiva de la protesta social La ley penaliza distintos repertorios de protesta, principalmente las ocupaciones y los bloqueos de vías públicas, sin que en la mayoría de los casos exista una precisa determinación de las conductas punibles (...), el Artículo 10 penaliza con prisión de 16 a 90 meses el "empleo o lanzamiento de sustancias u objetos peligrosos" en algunos lugares públicos, independientemente de contra quién 
se lancen; pero no establece qué es un "objeto peligroso", quedando su definición a discreción de las autoridades, ni menos cuándo tales acciones reúnen las condiciones para suponer que persiguen "fines terroristas" (...). Otra conducta sancionada con cárcel de dos a cuatro años, y del doble si se usa violencia, es la "perturbación de actos oficiales" (Art.15); tales "actos" están definidos de manera tan amplia que riñen con el Derecho a la Protesta y potencialmente se afecta el Derecho a la Libertad de Expresión. Los Artículos 60 y 61 declaran "procedente" la detención preventiva, hasta por 210 días, cuando "el mínimo de la pena prevista por la ley exceda cuatro (4) años de prisión". Además de penalizar conductas típicas de la protesta social, la falta de precisión de las normas antes mencionadas deja un amplio espacio de discrecionalidad a las autoridades de policía y a los operadores jurídicos, lo cual puede ir en detrimento del Derecho a la Protesta y los derechos a él vinculados. Todo eso enmarcado en un discurso de defensa del orden público, en el que predomina la seguridad nacional y la seguridad del Estado sobre la seguridad de los ciudadanos. Incluso podría afirmarse que en la ley se mantiene una visión contrainsurgente alineada a la guerra contra el terrorismo que, por ejemplo, se manifiesta en la prohibición a la utilización "ilícita" de redes comunicativas "con fines terroristas" (Art.8), sin precisar en dónde radica lo ilícito ni cuándo pueden determinarse los fines terroristas (Cruz, 2015. p.58).

En el análisis de Cruz (2015), se pueden comprender algunos aspectos de la ley, que se piensan en contra de los derechos fundamentales que establece la Constitución, elementos que son de gran importancia para entender la realidad que se vive hoy en día en el espacio público de la ciudad colombiana.

La situación de Colombia en la crisis de la pandemia por la Covid-19, durante los meses de abril a junio de 2021, donde se presentaron manifestaciones públicas en contra del gobierno con motivo de insatisfacciones de diversa índole, se puede describir como un escenario donde convergen múltiples acciones violentas en el espacio público que generan un ambiente caótico e inestable.

En el reporte de las ONG Indepaz y Temblores (Indepaz, 2021), y en el informe que contiene las observaciones y recomendaciones de la CIDH, producto de la visita a Colombia en el mes de junio de 2021 (CIDH, 2021), en los cuales se habla sobre las evidencias de las violaciones a los derechos humanos en el marco de las protestas realizadas durante el 28 de abril al 12 de mayo en Colombia, se analizan acciones y omisiones por parte del Estado que, como conjunto, generan un entorno propicio para la vulneración de derechos, especialmente el Derecho a la Protesta.

Desatención de medidas de salud pública y contención epidemiológica en el espacio público, utilización de la figura de "asistencia militar" para controlar centros urbanos, hechos registrados con altos niveles de violencia policial contra la población civil en diferentes lugares del país, presencia de agentes de la fuerza pública sin identificación o vestidos de civil, uso de armas de impacto desproporcionado, presencia de actores armados amparados por la fuerza pública, vandalización de infraestructura pública y privada, homicidio, lesiones personales, agresiones sexuales, desaparición forzada, cortes de servicios públicos, agitación y censura en redes sociales, agresiones a la fuerza pública, bloqueos, desabastecimiento de insumos de salud y alimentos, entre otros, son algunas de las acciones que se vivieron en diferentes ciudades del país durante las protestas sociales en los primeros meses de 2021.

Entonces ese escenario macabro en que se convierte el espacio público como contenedor de la realidad en Colombia, deja muchos interrogantes, por ejemplo: ¿Son estas acciones y manifestaciones las que representan a la sociedad colombiana? ¿Son hechos aislados de un momento en particular, o una historia que se repite continuamente en el país? ¿El espacio público colombiano ha sido vetado como escenario de dialogo necesario en toda sociedad democrática?

Se espera una transición de esta situación a realidades más democráticas, ese cambio urgente y necesario debe venir de cada uno de los actores de la sociedad para que pueda existir realmente una construcción colectiva como nación, un camino posible para todos, en armonía, y donde prime el respeto por las diferencias. 


\section{REFERENCIAS}

Borja, J.; Muxi, Z. (2003). El espacio público, ciudad y ciudadanía. Recuperado de https://www.researchgate. net/profile/Zaida-Martinez/publication/31731154_El_espacio_publico_ciudad_y_ciudadania_J_ Borja Z Muxi prol de O Bohigas/links/543fbcd00cf2be1758cf9779/El-espacio-publico-ciudad-yciudadania-J-Borja-Z-Muxi-prol-de-O-Bohigas.pdf

CIDH (2021). Observaciones y recomendaciones de la visita de trabajo de la CIDH a Colombia realizada del 8 al 10 de junio de 2021. Recuperado de: https://www.oas.org/es/cidh/informes/pdfs/ObservacionesVisita CIDH_Colombia_SPA.pdf

Cruz Rodríguez, E. (2015). El Derecho a la Protesta social en Colombia. Pensamiento Jurídico, (42), 47-69. Recuperado de https://revistas.unal.edu.co/index.php/peju/article/view/55404

INDEPAZ (2021). Informe CIDH violencia policial y protesta social en Colombia. Recuperado de: http://www. indepaz.org.co/wp-content/uploads/2021/05/INFORME-CIDH-VIOLENCIA-POLICIAL-PROTESTA$\underline{\text { SOCIAL.pdf }}$

Páramo, P., Burbano, A., Jiménez-Domínguez, B., Barrios, V., Pasquali, C., Vivas, F., Moros, O, Alzate, M., Jaramillo Fayad, J. C.\& Moyano, E. (2018). La habitabilidad del espacio público en las ciudades de América Latina. Avances en Psicología Latinoamericana, 36(2), 345-362. doi: https://doi.org/10.12804/ revistas.urosario.edu.co/apl/a.4874 